\title{
CORRIGENDUM
}

\section{Continuous mobility of mobile robots with a special ability for overcoming driving failure on rough terrain - CORRIGENDUM \\ $\mathrm{He} \mathrm{Xu}, \mathrm{X} . \mathrm{Z}$. Gao, Yan Xu, Kaifeng Wang}

Doi: 10.1017/S0263574716000606. Published by Cambridge University Press, 31 August 2016

The original version of this article listed the authors in the wrong order. The correct order is as follows:

He Xu, Yan Xu, Kaifeng Wang, X.Z. Gao, Khalil Alipour, Hongpeng Yu, Zhen Li, Ozoemena Anthony Ani.

The authors apologise for this error.

\section{Reference}

1. H. Xu, X. Z. Gao, Y. Xu, K. Wang, H. Yu, Z. Li, K. Alipour and O. A. Ani (2016) 'Continuous mobility of mobile robots with a special ability for overcoming driving failure on rough terrain', Robotica, pp. 1-21. doi: $10.1017 / \mathrm{S} 0263574716000606$. 